\begin{tabular}{|c|c|c|}
\hline & $\begin{array}{c}\text { Center A } \\
\text { (Rural Community Hospital) }\end{array}$ & $\begin{array}{c}\text { Center B } \\
\text { (Urban Academic Center) }\end{array}$ \\
\hline Patients (n,\%) & $963(35.0)$ & $436(15.8)$ \\
\hline Age (mean, SD) & $52.2(12.0)$ & $49.2(13.3)$ \\
\hline \multicolumn{3}{|l|}{$\operatorname{Sex}(n, \%)$} \\
\hline Male & $204(21.2)$ & $116(26.6)$ \\
\hline Female & $759(78.8)$ & $320(73.4)$ \\
\hline \multicolumn{3}{|l|}{ Comorbidities $(\mathrm{n}, \%)$} \\
\hline Anxiety & $300(31.2)$ & $59(13.5)$ \\
\hline Arthritis & $44(4.6)$ & $22(5.1)$ \\
\hline Asthma & $68(7.1)$ & $40(9.2)$ \\
\hline Back Pain & $139(14.4)$ & $24(5.5)$ \\
\hline COPD & $21(2.2)$ & $1(0.2)$ \\
\hline Cancer & $22(2.3)$ & $40(9.2)$ \\
\hline Depression & $368(38)$ & $79(18.1)$ \\
\hline Diabetes & $69(7.2)$ & $28(6.4)$ \\
\hline Heart Disease & $26(2.7)$ & $24(5.5)$ \\
\hline Hypercholesterolemia & $191(19.8)$ & $23(5.3)$ \\
\hline Hypertension & $228(23.7)$ & $106(24.3)$ \\
\hline Insomnia & $124(12.9)$ & $5(1.2)$ \\
\hline Irritable Bowel Syndrome & $36(3.7)$ & $16(3.7)$ \\
\hline Kidney Disease & $9(0.9)$ & $20(4.6)$ \\
\hline Liver Disease & $2(0.2)$ & $0(0)$ \\
\hline Lung Disease & $2(0.2)$ & $2(0.5)$ \\
\hline Migraine & $203(21.1)$ & $36(8.3)$ \\
\hline Osteoporosis & $43(4.5)$ & $37(8.5)$ \\
\hline Stroke (CVA) & $14(1.5)$ & $1(0.2)$ \\
\hline Thyroid Disease & $85(8.8)$ & 64 (14.7) \\
\hline Ulcer & $1(0.1)$ & $1(0.2)$ \\
\hline Other & $27(2.8)$ & $10(2.3)$ \\
\hline
\end{tabular}

Abstract 7 Figure 1 Year 2 Center C Results: Statistical Process Control (SPC) analyses describing the variation in performance compared to the overall average performance of the MSCQI Collaborative. Blue squares represent point esitimates, the green line represents the overall average, and red lines denote 3 Sigma upper and lower control limits. Points outside control limits (shown in red) indicate non-random (special cause) variation

MS population health outcomes using improvement science methods.

\section{TRANSITIONAL CARE CENTER: A CENTER FOR MEDICAL AND NON-MEDICAL EXCELLENCE}

${ }^{1}$ Nkem Chukwumerije, ${ }^{2}$ Parnika Kodali. 'SCAL Permanente Medical Group, USA; ${ }^{2}$ Kaiser Hospital Health Plan, USA

\subsection{6/bmjoq-2019-ihi.8}

Background In 2016, in PCMC, only 75\% high risk patients were receiving post hospital follow up care. Given that $24 \%$ of our high-risk patients are readmitted, it is fair to assume that no follow up results in higher utilization. For those that did receive follow up, it was variable depending on the physician. Primary care offices did not have a robust process for social needs evaluation. Hence, patients used more ED services for social needs. Programs that address both medical and non medical needs of patients show higher success but are often limited.

Objectives Reduce utilization by addressing medical and nonmedical needs of high-risk patients.

Methods TCC appointment consists of: 40-minute medical assessment by a physician, pharmacist lead medication reconciliation, social worker assessment for social and behavioral needs, care navigator to secure resources, and care coordinator to manage the care plan for upto 90 days.

Results A single centered retrospective study was used to evaluate pre and post utilization of high risk patients that were treated in TCC and a similar control group that received care with a PCP. The demographics of both groups were evaluated to ensure similar representation. The results showed a significant decrease in utilization for the TCC patients compared to 


\begin{tabular}{|l|c|c|c|c|}
\hline $\begin{array}{c}\mathrm{n}=148 \\
\text { All Unique M } \\
\text { RNS }\end{array}$ & Pre & Post & $\Delta$ & $\begin{array}{c}\text { Cost Avoidance } \\
\text { (Loaded Costs) }\end{array}$ \\
\hline ED (Visits) & 827 & 404 & 423 & $\$ 216,153.00$ \\
\hline UC (Visits) & 278 & 191 & 87 & $\$ 10,440.00$ \\
\hline IP (days) & 992 & 371 & 621 & $\$ 2,079,729.00$ \\
\hline Observations & 472 & 204 & 268 & $\$ 897,532.00$ \\
\hline
\end{tabular}

$\$ 3,203,854.00$

\section{Abstract 8 Figure 1}

the control group yielding in approximately $\$ 2,145,099$ in cost avoidance. In addition, 1:1 pharmacist time showed a projected cost savings of $\$ 385,000$.

Conclusions Connecting patients and families with appropriate resources and supporting them will increase the quality of care and patient adherence to the care plans which in turn decreases utilization.

\section{A POSTOPERATIVE PROTOCOL REDUCES OPIOIDS PRESCRIBED AFTER PEDIATRIC ORTHOPAEDIC SURGERY}

${ }^{1}$ Kirsten Ross, ${ }^{2}$ Joseph Gibian, 'Jeffrey Martus, ${ }^{3}$ David Johnson, 'Megan Johnson. ${ }^{1}$ Vanderbilt University Medical Center Department of Orthopaedic Surgery, USA; ${ }^{2}$ Vanderbilt University School of Medicine, USA; ${ }^{3}$ Vanderbilt University Medical Center Department of Pediatrics, USA

10.1136/bmjoq-2019-ihi.9
Background Wide variability exists in opioid doses prescribed after pediatric orthopaedic surgery. Increasing opioid prescriptions by a single day increases the risk of aberrant opioid behavior by almost $10 \%$ in the pediatric population.

Objectives The goal of this study is to increase the percentage of patients prescribed opioids based on a standard dosing protocol after pediatric orthopaedic surgery from 0 to $90 \%$.

Methods A multidisciplinary team developed a key driver diagram (figure 1). A prescribing protocol was developed based on the surgery severity. Baseline data began in October 2017 with initial protocol testing starting in November 2017. The primary measure was the weekly percent of patients correctly dosed by the protocol. The secondary measure was the average number of opioids prescribed at discharge each week for all children undergoing orthopaedic surgery between October 2017 and September 2018. Statistical process control charts were used for data analysis with Nelson rules used to determine special cause.

Results 1645 patient records were prospectively reviewed during the study time period. Adherence to the dosing protocol increased from $0 \%$ at baseline to $97 \%$ for all categories of surgery (figure 2). Mean prescribed opioid doses following surgical procedures were reduced from 21.9 to 17.8 doses (figure 3), achieving special cause variation.

Conclusions Implementation of a standardized opioid dosing protocol for pediatric patients undergoing orthopaedic surgery improved protocol-based adherence to over $90 \%$ and was associated with reduced opioid doses prescribed at discharge. Future work will investigate whether this may lead to a decrease in aberrant opioid behaviors in pediatric patients. 